\title{
Subjetividades contemporâneas e escrita biográfica: limites, desafios e possibilidades
}

\author{
Alexandre de Sá Avelar*
}

Apenas a matéria vida era tão fina

Caetano Veloso - Cajuína

\section{Tecnologias, subjetividades e controle: a paisagem contemporânea e o indivíduo}

A nossa época operou uma transformação radical nas configurações da subjetividade e, talvez por esta mesma razão, enfrenta uma situação paradoxal: poucas vezes se falou tanto em desconstrução do sujeito ao mesmo tempo em que se verificou uma explosão de identidades. Essa recomposição das formas de sentir, pensar e de se posicionar no mundo alterou os significados da existência individual, originando novas modalidades de construção de si, assim como interditou outras (Sibilia, 2009, p. 19).

A mutação das sensibilidades e das figurações da interioridade atravessa toda a história ocidental da noção de sujeito e não constitui, nesse sentido, qualquer novidade epistemológica. Essa transitoriedade do eu já poderia ser vista, em texto de 1938, na pena de Marcel Mauss (1950, p. 339, 362, tradução minha), para quem "a noção de pessoa, longe de ser uma ideia primordial, inata, e claramente inscrita $[\ldots]$ no mais profundo do nosso ser, $[\ldots]$

* Professor do Instituto de História da Universidade Federal de Uberlândia (UFU). 
permanece imprecisa, necessitando de uma maior elaboração”. Num exercício genealógico, poderíamos mesmo remontar essas considerações às turbulentas experiências da modernização em sua destruidora diluição de tudo o que parecia sólido.

O advento da modernidade significou uma reconfiguração das noções de público e privado, com a expansão da intimidade nos limites do lar. Os atos de leitura e escrita convocavam um indivíduo solitário enclausurado na privacidade doméstica e apontavam para um processo de interiorização desses atos. Subsistia a presença de territórios relativamente bem definidos, que formatavam aquelas noções. A distinção fundamental operada pelos meios eletrônicos e digitais do mundo contemporâneo reside cada vez mais na indistinção entre as esferas pública e privada, com o abandono do sistema clássico de um emissor para muitos receptores. Uma dupla tendência ganha fôlego: cada vez mais privatização individual e cada vez menos refúgio na própria interioridade (Sibilia, 2009, p. 56).

A proliferação diária de biografias espetacularizadas é, sem dúvida, um dos sinais desse processo. $\mathrm{Na}$ exteriorização generalizada, "tendemos a ser contadores de histórias compulsivos e encontramos poucos ou nenhum tópico mais interessante que nós mesmos para as nossas histórias - nossas emoções, sensações e mais íntimas experiências" (Bauman, 2008, p. 17). O vivo interesse por trabalhos biográficos - refletindo-se numa pluralidade de públicos, leitores e audiência - talvez exceda a simples lógica de mercado ou os apelos que sempre parecem exercer os personagens notáveis. A multiplicação de relatos autobiográficos, de entrevistas, perfis e escritas de vidas de personagens ilustres ou não pode ser indicativa de uma "tonalidade particular da subjetividade contemporânea” (Arfuch, 2010, p. 17, tradução minha). O mercado editorial de obras biográficas atesta a vitalidade do gênero em nossos dias. Este fato não aponta somente para o sucesso comercial dos relatos de vida, das autobiografias e das diversas formas de textualização do eu. Trata-se também da reatualização da aposta biográfica que motivou sucessivas gerações a compreender o outro, utilizando os diversos instrumentos dos quais dispunham. As perguntas formuladas, as lacunas documentais e os novos questionamentos realizados, muitas vezes em direção a personagens já exaustivamente estudados, são sinais da inquietude própria que inscreve a biografia, em primeiro lugar, em nossa relação com o presente.

A epistéme pós-moderna aponta para uma mudança paradigmática de enorme importância. Estaríamos ingressando em uma nova forma de 
organização social, distinta da sociedade disciplinar que marcou o período entre os séculos XVIII e XX, e que foi tão bem estudada por Michel Foucault. Como em outros momentos, o novo modelo articula a presença de determinadas expressões de subjetividade e de formatação das experiências identitárias e a exclusão de outras. Essa sensível ampliação do horizonte produtor de narrativas de si e de relatos do eu não está isenta de formas de cooptação e de forças que tendem a enquadrar as energias criadoras nos fluxos históricos nem sempre visíveis de práticas e discursos. $\mathrm{O}$ consumo desenfreado, a produção midiatizada do capitalismo contemporâneo e a expansão dos meios tecnológicos e informacionais edificam os pilares das sociedades de controle, na acepção deleuziana.

Segundo Deleuze (1992), as sociedades de controle situam-se no limiar de uma situação histórica de crise dos instrumentos tradicionais que confinavam os indivíduos em espaços normatizados por regras disciplinares claramente discerníveis: prisões, hospitais, fábricas, escolas, famílias. Recuperando Foucault, afirma que esses meios de confinamento teriam como projeto concentrar, distribuir no espaço, ordenar no tempo e compor no espaçotempo uma força produtiva cujo efeito deve ser superior à soma das forças elementares. (Deleuze, 1992, p. 219). Essa conjunção específica de práticas, instituições e saberes configurava as sociedades disciplinares cujas linhas de força teriam entrado em colapso após a Segunda Guerra Mundial em favor de outro sistema, de outra forma de arranjo societal.

Os regimes disciplinares operavam a partir de confinamentos como moldes que tendiam à fixação dos indivíduos nas malhas de saberes e práticas socialmente aceitas. Nas sociedades de controle, falamos mais coerentemente de modulação "como uma moldagem autodeformante que mudasse continuamente, a cada instante, ou como uma peneira cujas malhas mudassem de um ponto a outro" (Deleuze, 1992, p. 221). A expressão que talvez melhor assinale a mutação que se dá com a emergência do controle é o surgimento da empresa. Segundo Deleuze (1992, p. 221):

A fábrica constituía os indivíduos em um só corpo, para a dupla vantagem do patronato que vigiava cada elemento na massa, e dos sindicatos que mobilizavam uma massa de resistência; mas a empresa introduz o tempo todo uma rivalidade inexpiável como sã emulação, excelente motivação que contrapõe os indivíduos entre si e atravessa cada um, dividindo-o em si mesmo. 
Nas sociedades de controle, os indivíduos tornaram-se dividuais, divisíveis, e as massas, amorfas ou simples bancos de dados (Deleuze, 1992, p. 222). Toda essa realidade corresponde a uma mutação significativa no funcionamento do capitalismo, agora regido pela dispersão e dirigido para a propaganda e a venda de serviços. O controle torna-se instantâneo, contínuo e ilimitado, ao passo que a disciplina era de longa duração, infinita e descontínua. Por outro prisma, Haroche (2008, p. 123) analisou a fluidez contemporânea sob a égide da globalização:

Sob o impacto da globalização, as sociedades contemporâneas tendem a se tornar sociedades que se transformam de maneira contínua; sociedades flexíveis, sem fronteiras e sem limites; sociedades fluidas, líquidas. Tais condiçôes têm consequências sobre os traços de personalidade, dos mais contingentes e superficiais aos mais profundos, sobre os tipos de personalidade que tendem a desenvolver, e mesmo encorajar, e também sobre a natureza das relações entre os indivíduos. A fluidez destituída intrinsecamente de limites acarreta modificações nas estruturas e pode pôr em questão a possibilidade de estruturação e mesmo de existência do eu. É possível pensar imerso na fluidez, sob pressão permanente e ininterrupta do fluxo? Privado de tempo, da duração exigida pelos sentimentos, o indivíduo hipermoderno pode experimentar algo diferente de sensaçôes?

Nas sociedades de controle, a individualização torna-se uma tarefa vigiada por todo o tecido social. A obrigação de ser distinto, de possuir um conjunto peculiar de características próprias invade constantemente cada personalidade individual a ponto de que, numa "sociedade de indivíduos, cada um deve ser um indivíduo" (Bauman, 2007, p. 26). A aporia da individualidade na sociedade de controle consiste no fato de que a busca por se tornar diferente faz com que todos acabem se assemelhando cada vez mais. Assim, ser indivíduo é uma exigência de um aglomerado e só, paradoxalmente, deixando-se de ser um sujeito único é que se pode passar a um estado de efetiva dissociabilidade em relação ao restante.

Já que ser um indivíduo comumente se traduz por ser "diferente dos outros" e é do "eu" que se espera destaque, a tarefa parece intrinsecamente autorreferencial. Parece que quase não temos escolha senão buscar um indício de como se aprofundar cada vez mais no 'interior' de nós mesmos, 
aparentemente o nicho mais privado e protegido num mundo de experiências parecido com um bazar lotado e barulhento. Eu procuro pelo meu 'verdadeiro eu' que suponho estar escondido em algum lugar da obscuridade do meu eu prístino, não afetado (não poluído, não suprimido, não deformado) pelas pressões externas. (Bauman, 2007, p. 27).

$\mathrm{Na}$ era dos controles, o que se pode esperar da sociedade é a produção incessante de estímulos à individualidade de todos e de cada um. Aqui, mais uma vez, talvez seja pertinente evocar as considerações de Deleuze sobre o papel da empresa no capitalismo contemporâneo, em sua intensa competição não apenas por mercados, mas também entre seus próprios funcionários através de bonificações por mérito e também de "desafios, concursos e colóquios extremamente cômicos” (Deleuze, 1992, p. 221). A reprodução do capital se dará tão mais efetivamente quanto maior for sua capacidade de fabricar individualidades. Controles e mercados coexistem na intensa produção de individualidades adequadas ao novo regime social, no qual o homem é ondulatório, funcionando em órbita, num feixe contínuo (Deleuze, 1992, p. 223).

$\mathrm{Na}$ busca incessante por nos tornarmos únicos, a constante exposição dos nossos sentimentos é outra estratégia aparentemente sensata, pois serve para demonstrar aos outros o quanto estamos atentos à nossa diligente tarefa de sermos diferentes. Como nos recorda Bauman (2007, p. 28), os sentimentos "parecem o habitat natural de tudo o que é totalmente privado e individual". Essas modalidades de exibição do "eu” assumem, em nossa época, cada vez mais, a forma de visualizações midiáticas e digitais.

Um dos campos privilegiados de observação da individualidade contemporânea é, sem dúvida, o espaço virtual, signo de uma cultura midiatizada que expande o espectro de criação de memórias. Esse movimento traz no seu bojo a alimentação da própria amnésia, pois a "velocidade sempre crescente das inovações técnicas, científicas e culturais gera quantidades cada vez maiores de produtos que já nascem obsoletos" (Huyssen, 2000, p. 27). Como resultante dessa avalanche de transformações que parecem tornar o presente a condição normal da existência, os indivíduos tendem a buscar refúgio no passado, produzindo uma "memorização fanática, uma fascinação pelas comemorações” (Baudrillard, 2001, p. 46). Presos no presente, não conseguem compor uma experiência temporal coerente e experimentam a fragmentação de suas referências, conforme nos aponta Fredric Jameson (1996, p. 52): 
Se, de fato, o sujeito perdeu sua capacidade de entender de forma ativa suas pretensões e retenções em um complexo temporal e organizar seu passado e seu futuro como uma experiência coerente, fica difícil perceber como a produção cultural de tal sujeito poderia resultar em outra coisa que não um amontoado de fragmentos e uma prática da heterogeneidade a esmo.

As representações individuais construídas no mundo virtual oferecem um intrincado campo de interrogações àqueles interessados em perscrutar os caminhos de uma existência. Não está ainda claro, por exemplo, qual o estatuto teórico-documental que terão, para os historiadores-biógrafos, os sites de relacionamento, os blogs, o Youtube etc., espaços digitais de gestação de novas formas de relacionamento e de técnicas de si em um campo de produção de individuação (Deleuze, 1990, p. 128). Essas demonstrações do eu, não raro, transitam entre a mais eloquente megalomania e a mais singela mediocridade, a mais grandiosa pretensão de potência e a mais particularizada sensação de sentir-se "apenas mais um" na vastidão do ciberespaço.

As formas de exibição da personalidade que proliferam na web sinalizam para outra problemática: em que medida elas constituem vestígios de uma escrita autobiográfica ou simplesmente mostram a vida de seus autores? Estamos diante de obras ou vidas? Ou se trata de um novo gênero, capaz de diluir todas as fronteiras anteriores? São obras produzidas por artistas que encarnam uma nova forma de arte ou apenas documentos de uma existência desnudada?

Seguiremos, na tentativa de ensaiar algumas respostas para esses problemas, as reflexões de Paula Sibilia. As expressões e os relatos de si veiculados em formatos midiáticos não operam, de forma absoluta, com modalidades de escrita distintas dos relatos ficcionais. Esses usos confessionais, por outro lado, também não se mostrariam distantes das já conhecidas fórmulas autobiográficas. $\mathrm{O}$ sujeito que se apresenta é, simultaneamente, personagem, narrador e autor. Não obstante a complexidade e a fluidez inscritas em cada eu, a narrativa da existência é essencial, na medida em que nos situa no mundo, é a matéria que nos constitui (Sibilia, 2009, p. 37). Suas profundas imbricações com o ficcional não devem obscurecer o fato de que nossa construção subjetiva depende da nossa capacidade de organizar nossas experiências e de torná-las textualizáveis.

As cadeias discursivas são lugares de produção de significados e de subjetividades. $\mathrm{O}$ uso de palavras e imagens é nossa própria atuação no mundo, 
nosso estar presente. São elas que nos ajudam a conferir sentido ao fluir tumultuado de nossas existências, ao mesmo tempo em que organizam o tempo e o espaço em diálogo com outras vozes e experiências que nos atravessam (Sibilia, 2009, p. 38). Essas outras subjetividades possuem capacidade de afetar as nossas próprias e não há relato biográfico que não esteja habitado pela alteridade, pois "toda comunicação requer a existência do outro, do mundo, do alheio e do não eu" (Sibilia, 2009, p. 38, tradução minha). Formatada e significada pela narrativa, a vida não encerra, em si mesma, algum sentido que esteja dado antes do relato.

É de se interrogar, entretanto, qual o estatuto narrativo das exibições do eu no espaço midiático, especialmente em blogs e em redes de relacionamento interpessoal. A figura do narrador foi dilacerada na modernidade, de acordo com Walter Benjamin, pela velocidade e pelo impacto da circulação de informações, que teriam diluído as formas tradicionais de narração. A exigência de verificação imediata que caracteriza o gênero informativo "deve ser compreensível em si e para si” (Benjamin, 1994, p. 202) e guardar alguma referência com o real. Essas qualidades da informação devem ser acrescentadas à outra que, em Benjamin, delimita uma distinção fundamental entre as narrativas tradicionais e as modernas: enquanto nas primeiras a palavra narrada conserva um horizonte interpretativo relativamente aberto, nas segundas, sob o signo da informação, as explicações são todas oferecidas de forma mais imediata, para consumo rápido, sendo permanentemente atualizáveis.

\section{Os (tortuosos) caminhos da escrita biográfica na contemporaneidade}

As considerações acima servem de preâmbulo para nossa questão fundamental: a escrita biográfica ainda pode ter a pretensão de oferecer um relato coerente e estável de uma personalidade? Ou, em outras palavras: a vida é narrável através de uma moldura textual? Qual o limite da tensão entre historicidade e ficcionalidade, "uma vez que ao escrever a história de um indivíduo a imagem de sua vida é construída e reconstruída pelo biógrafo?” (Neves, 2011, p. 305).

A crise dos grandes projetos coletivos de transformação social, a descrença cada vez maior nos modelos clássicos de representação política e o recuo dos valores do estado de bem-estar social abriram caminho para uma 
expansão sem limites das vozes subjetivas, das identidades fragmentadas e precárias, da personalização da política. Portanto, em nosso atual regime de historicidade, denominado de "presentista” por François Hartog (1997), não parece haver dúvida quanto à pertinência dos pequenos relatos, das experiências cotidianas e da redução da nossa escala de análise em direção ao microscópico e ao vulgar. Admite-se, com menos conflitos e armas em punho, que o caráter da narrativa histórica está imerso em tropos literários que não podem ser negligenciados pelo historiador.

As aproximações entre texto historiográfico e literário são bem conhecidas. Elas guardam relação direta com o "giro linguístico" que, apesar da grande variedade de autores e correntes, enfatiza a ideia da inexistência de uma realidade extralinguística independente das representações textuais e discursivas. O real, nessa ótica, só pode nos chegar através de um texto cujos sentidos e significados não apontam diretamente para o mundo exterior, mas para outros textos e signos. É para esse sentido que Frank Ankersmit (2001, p. 113) aponta quando afirma que "estamos familiarizados com a ideia de que, em qualquer área da historiografia que possamos imaginar, em qualquer especialização, uma quantidade superabundante de artigos e livros é produzida anualmente, tornando conhecê-los todos tarefa impossível”. O campo do conhecimento histórico é composto por discursos litigiosos, por obras que apenas remetem a outros trabalhos historiográficos. Não há uma base de sustentação que possa assegurar a correspondência entre os conteúdos narrativos e o acontecido. Isto significa conceber a linguagem tanto como representação do passado quanto como instituidora da realidade, e admitir que nosso conhecimento é social e estruturado a partir de determinadas práticas de poder culturalmente determinadas.

A crença na unidade da escrita biográfica, capaz de apresentar a vida do personagem como um conjunto coerente de ações e sentimentos, foi entendida por Pierre Bourdieu (1996, p. 184) como uma "ilusão", que "transcorre, segundo uma ordem cronológica que também é uma ordem lógica, desde um começo, uma origem, no duplo sentido de ponto de partida, de início, mas também de princípio, de razão de ser, de causa primeira, até seu término, que também é um objetivo". A coerência que o biógrafo imagina inscrever no seu trabalho não encontra correspondência no real, pois este "é descontínuo, formado de elementos justapostos sem razão, todos eles únicos e tanto mais difíceis de serem apreendidos, porque surgem de modo incessantemente imprevisto, fora de propósito, aleatório" (Bourdieu, 1996, p. 185). 
Se a realidade não possui qualquer significação unificadora, as narrativas de vida, organizadas em função de uma explicação final para a trajetória individual, são simples artifícios contra a falta de sentido do mundo. Estaria nessa construção fictícia o grande equívoco do biógrafo. Ele imagina poder dotar de sentido uma existência que é sempre fraturada, atravessada por tensões e conflitos, disposta em fragmentos.

A noção de uma narrativa biográfica construtora de sentidos fixos, homogêneos e permanentes para uma trajetória singular só era possível num regime de historicidade que admitisse a existência de uma contiguidade temporal entre o presente e o passado. A biografia, nessa configuração intelectual cientificista, cumpria funções distintas, ora servindo como repositório de exemplos, ora como acesso às grandes tendências coletivas. Em ambos os casos, acreditava-se na possibilidade de restituição de uma identidade fugidia por intermédio da articulação narrativa que, em última instância, se alinhava a uma concepção de continuidade entre sujeito e história. O efeito discursivo daí resultante era o de uma história coerente e totalizante, ainda que sob o preço de uma atividade ficcional ou de uma criação artificial de sentido. A linearidade do relato biográfico, a certeza da possibilidade de representação de uma vida a partir de uma narrativa coerente e o enquadramento retrospectivo e prospectivo da existência individual sugerem a segurança que parece se perder na torrente da multiplicação das identidades e dos relatos de si.

As reflexões teóricas pós-estruturalistas produziram incontáveis ganhos para o historiador. Fizeram com que ele percebesse a natureza profundamente histórica e condicionada do seu relato, as dimensões ficcionais contidas em sua narrativa e as incertezas e as incoerências da noção moderna de sujeito. No caso da biografia, em específico, alertaram para os perigos e os riscos de pensar uma vida como uma unidade estável. O enfrentamento dos desafios contemporâneos da escrita biográfica deverá considerar sua indistinção epistemológica, seu pêndulo oscilante entre mimesis e vidas imaginárias. Os historiadores devem, portanto, escrever suas biografias dentro de um novo quadro de referências ante o declínio dos grandes paradigmas explicativos que sustentaram a pesquisa histórica ao longo de boa parte do século XX. O que está em jogo agora "é a importância de uma experiência singular mais que a de uma exemplaridade destinada a encarnar uma verdade ou um valor geral, ou ainda a convergir para um destino comum" (Revel, 2010, p. 242). As trajetórias singulares devem demonstrar o que não volta ao quadro geral - hesitações, incoerências, incertezas, transformações. Para tanto, o biógrafo 
transita por distintas temporalidades, o que implica o abandono da linearidade cronológica. Assim, ganham forma o tempo "contextual" (o cenário político, econômico, cultural), o tempo familiar, o tempo interior, o tempo da memória (Schmidt, 2000, p. 199). Para Dosse (2009, p. 297):

O moderno regime de historicidade desconstrói as figuras tutelares que se prestam à identificação. Essa desconstrução abre possibilidade para as figuras plurais. O biógrafo pode então fazer o melhor dos índices mais corriqueiros para compor relatos biográficos segundo as linhas da intensidade múltipla. A linearidade postulada pela biografia clássica já não será então considerada intocável. $\mathrm{O}$ fato de se considerar o homem como fundamentalmente plural, mantenedor de vínculos diversos, modifica a abordagem do gênero biográfico.

De acordo com Diana Damasceno (1999, f. 97), “escrever biografias em nossos dias requer consciência aguda do processo de reinterpretar o passado como forma particular de construção, sujeita a variados desdobramentos, levando em conta que vidas podem ser entendidas como sistemas complexos". Essa complexidade só pode ser pensada se o biógrafo abdicar da noção de linearidade em favor da de simultaneidade. Não apenas os estados da personalidade podem ser simultâneos, mas a própria memória individual que se quer resgatada é simultânea ao presente, e não um fragmento perdido no passado. Ela ganha forma pela e através da escrita, esse inconfundível recurso que dá sentido à ausência, inscrevendo-na em outro tipo de presença. Segundo Adriana Amaral (2000, p. 34),

Essa capacidade de atravessar contextos da escritura é que faz a presença feita de ausência, onde a ausência na verdade se funde na presença em um presente que se faz a cada novo instante, a cada novo contexto. [...] A marca (da escrita) garantirá a repetição em qualquer contexto, visto que nenhum contexto se fecha mais sobre si mesmo e tampouco possui um centro absoluto. Ora, esse atravessar de contextos é próprio da escrita se comparada com a fala, que deixa inclusive de ser uma oposição quando se pensa que ela também é feita de referência e não da coisa em si.

O personagem biografado é, nessa ótica, um personagem que se apaga e se inscreve novamente na escrita do biógrafo. Tal como sua identidade 
fractal, sua inscrição narrativa é fugidia, incerta, pois suas ações e experiências não podem ser recuperadas em seus momentos originais. Durval Muniz Albuquerque Júnior $(2007$, p. 48) remete essa configuração despedaçada da individualidade à figura do migrante, pois

este sujeito que parte é um sujeito partido, fragmentado, não é uma unidade, uma totalidade. Assim como a sua vida é errante e aberta, ele, enquanto sujeito, é também um sujeito aberto, atravessado por diferentes fluxos sociais. Ele não consegue totalizar as experiências que passam por ele mesmo, que o atravessam. Ele é um entroncamento em que diferentes estradas, diferentes séries históricas vêm encontrar-se e, ao mesmo tempo, vêm separarse. [...] Este sujeito segmentado e nômade é, dificilmente, aprisionado por grades conceituais com perspectivas totalizadoras.

A dissolução da identidade discernível do sujeito, seu enquadramento em uma pluralidade de narrativas e discursos e as diversas possibilidades de apresentação de uma vida são questões que se encontram no centro dos debates sobre a sociedade contemporânea. Elas também não escaparam ao olhar inquieto e desafiador de Michel Foucault. Suas formulações sobre essas problemáticas ainda não foram suficientemente exploradas pelos historiadores dedicados ao estudo do gênero biográfico, razão pela qual acreditamos serem pertinentes algumas referências, ainda que breves, ao seu trabalho sobre dois indivíduos aparentemente destituídos de maior interesse.

Autor pouco lembrado no que se refere aos estudos sobre biografia, o filósofo francês coordenou, em 1978, uma coleção provocativamente chamada de Vidas paralelas, quando apresentou o caso da hermafrodita Herculine Barbin, que se suicidou em 1868 por asfixia. Um pouco antes, em 1973, tornou conhecido o espantoso crime do parricida Pierre Rivière, assassino confesso da mãe, da irmã e do irmão. Os dois indivíduos foram mostrados por vias pouco convencionais: aquelas dos discursos médico e legalista e também dos próprios relatos autobiográficos escritos por ambos. Essas memórias foram transcritas em estado bruto, sem maiores comentários de Foucault. O procedimento biográfico do filósofo francês consistiu em confrontar essas modalidades de escrita de si com os discursos e os postulados normativos das instâncias de poder que se propuseram a esclarecê-las: a justiça e a medicina. $\mathrm{Na}$ apresentação de Vidas paralelas, Foucault (1994, p. 499) justificou da seguinte forma suas intenções: 
Os antigos gostavam de colocar em paralelo as vidas dos homens ilustres; escutava-se falar através dos séculos dessas figuras exemplares. As paralelas, bem sei, são feitas para se reunirem no infinito. Imaginemos outras que, indefinidamente, divergem. Sem ponto de encontro, nem lugar para as recolher. Frequentemente, elas não tiveram outro eco senão o de sua condenação. Seria necessário apanhá-las na força do movimento que as separa; seria necessário redescobrir o rastro instantâneo e fulgurante que elas deixaram quando se precipitaram para uma obscuridade onde "isso já não conta” e onde todo o "renome" é perdido. Seria como o inverso de Plutarco: vidas a tal ponto paralelas que já ninguém as pode reunir.

Se, em Plutarco, as vidas dignas de serem resgatadas deveriam oferecer exemplos para a posteridade, em Foucault o interesse se desloca para as existências afastadas da glória, da exemplaridade, do reconhecimento perpétuo. As vidas que pretende investigar não podem se reunir em nenhum ponto; o paralelismo aqui é pensado como a radicalização dessas trajetórias singulares. Suas falas e atos são negados e destituídos de valor. São vidas esquecidas, não rememoradas, precipitadas para a obscuridade, desfiguradas em arquivos esquecidos e, não raro, enquadradas em discursos extemporâneos, produzidos por outros, desfocados. No caso específico de Pierre Rivière, o discurso jurídico e o médico o enquadravam dentro de duas cadeias normativas: o Rivière criminoso sem qualquer desvio psíquico e o Rivière alienado mental desde a infância. Diante destas perspectivas opostas, o relato do próprio criminoso é interpretado binariamente. De acordo com os médicos, ele revela um problema mental já antigo; para os magistrados, o texto prova a plena responsabilidade do réu, capaz, afinal, de traçar sua autoanálise. Estamos diante de uma instigante e ainda pouco explorada via de estudo biográfico, como aponta o próprio Foucault (1987, p. 272, nota 67):

Seria necessário estudar como a prática da biografia se difundiu a partir da constatação do indivíduo delinquente nos mecanismos punitivos; biografia ou autobiografia de prisioneiros em Appert; estabelecimento de dossiês biográficos sobre o modelo psiquiátrico; utilização da biografia na defesa dos acusados. Sobre este último ponto poderíamos comparar as grandes memórias justificativas do fim do século XVIII para os três homens condenados à roda, ou para Jeanne Salmon - e as defesas criminais da época de Luis Filipe. Chaix d'Est-Ange defendia La Roncière: "Se muito tempo antes do crime, muito tempo antes da acusação, podeis escrutar a vida do acusado, penetrar 
em seu coração, sondar seu âmago mais escondido, pôr a descoberto todos os seus pensamentos, sua alma inteira $[\ldots]$.

O "rastro instantâneo e fulgurante" é a prova, entretanto, de que essas trajetórias não se silenciam por completo e, em meio a cruzamento, choque e anulação entre discursos, leis, enunciados científicos, proposições morais, técnicas de si, há a tomada da palavra pelo indivíduo infame. Os relatos autobiográficos de Rivière e Barbin mesclam-se à teia discursiva mais ampla, compondo mais um acontecimento histórico que, longe de enunciar uma verdade sobre seus autores, produz mais um sentido para essas trajetórias. A escrita não aparece como propriedade e expressão derivadas de um autor exterior a ela. Ela não é a verdade de uma vida, mas um momento dela. $\mathrm{O}$ indivíduo constitui-se historicamente nessa escrita, revelando experiências e práticas que são abertas, múltiplas, e que podem ser inscritas em outros tantos enunciados narrativos.

A dispersão de discursos que envolvem a construção da subjetividade de Rivière e de Barbin aponta para a dessacralização, realizada por Foucault, da noção de sujeito, tomado aqui como um entrecruzamento de falas - incluída a do próprio indivíduo - e não como uma unidade previamente dada. $\mathrm{O}$ sujeito é construído culturalmente por intermédio de operações específicas e complexas. O filósofo francês rejeita uma universalidade, uma autonomia plena de consciência e uma liberdade de ação abstrata tal como se postula em diversos discursos biográficos, pois "nada no homem - nem mesmo seu corpo - é bastante fixo para compreender outros homens e se reconhecer neles" (Foucault, 1999, p. 27). Não há, portanto, no homem "uma identidade esquecida, sempre pronta a renascer, mas um sistema complexo de elementos múltiplos, distintos, que nenhum poder de síntese domina” (Foucault, 1999, p. 34). Os textos autobiográficos são lidos por Foucault dentro da sua análise arqueológica, descrevendo o nível das práticas discursivas e dos saberes em que se encontram engajados, que definem uma perspectiva legítima para o agente do conhecimento e que fixam normas para sua elaboração. Estas, "em sua heterogeneidade, não formam nem uma obra, nem um texto, mas uma luta singular, um confronto, uma relação de poder, uma batalha de discursos e através de discursos" (Foucault, 2003, p. 12). Em suma: esses discursos estão imersos em um sistema de regras que definem exclusões e opções, regras que não são formuladas pelos seus participantes e que não são transparentes em suas consciências. 
A crítica foucaultiana à noção de autor é acompanhada de perto pela desconfiança em relação à biografia como forma fixa de representação do indivíduo. O discurso biográfico visa a reduzir uma vida a alguns traços, marcas, ignorando o quanto a existência ultrapassa largamente qualquer escrita. $\mathrm{O}$ esforço em escrever biografias faz parte de um processo de construção, no mundo ocidental, da noção de indivíduo, cuja trajetória exprime uma singularidade que pode ser apreendida racionalmente pelos instrumentos de pesquisa e análise que a racionalização científica vai forjando. Indivíduo, autor, identidade são categorias do pensamento que visam a produzir uma normalização do corpo e sua inscrição numa dada forma de elaboração linguística. Tudo isso não significa, para Foucault, a total rejeição da biografia, mas o entendimento de que sua escritura "é uma escavação ao infinito, em que jamais se chegará a uma imagem definitiva do biografado. Será sempre possível, como o discurso médico e o discurso jurídico fizeram com Rivière, esculpir novas figuras do sujeito e lhe atribuir o mesmo nome" (Albuquerque Júnior, 2007, p. 117).

Portanto, Foucault está muito distante do procedimento biográfico tradicional, entendido por ele como uma modalidade de normalização da existência. Barbin e Rivière não são apanhados na totalidade de suas trajetórias. Eles são configurações históricas formadas pelo cruzamento, o choque, a articulação ou a anulação entre discursos, instituições, postulados científicos, práticas e técnicas de si. Narrar uma vida só pode ter algum sentido se forem abandonadas as noções de sujeito e autor tais como eram pensadas em nossa tradição cultural. As interações entre indivíduos e grupos produzem distintos modos de sentir, pensar e experimentar o mundo, abrindo caminho para múltiplas narrativas do eu. O discurso biográfico normatizador da vida "categoriza o indivíduo, marca-o com sua própria individualidade, liga-o à sua própria identidade, impõe-lhe uma lei de verdade, que devemos reconhecer e que os outros têm que reconhecer nele" (Foucault, 1995, p. 235). Produz, dessa forma, mais um elo da cadeia de discursos que buscam disciplinar os corpos e atribuir-lhes sentidos extemporâneos.

\section{À guisa de conclusão: uma hermenêutica de si?}

Como bem lembra Giovanni Levi, a biografia se prestou a diversos usos. Houve épocas em que se imaginava poder contar a vida de um indivíduo sem 
maiores preocupações com o contexto ou com os sistemas normativos. Em outras, o indivíduo foi sumariamente descartado, em virtude da sua pouca utilidade para explicar os grandes fatos históricos ou as correntes de causalidade entre os mais variados eventos. Estaríamos, atualmente, em um momento intermediário: ao mesmo tempo em que o gênero biográfico está no núcleo das práticas historiadoras contemporâneas, suas ambiguidades e incertezas são claramente denunciadas. Muitas delas são resultantes da "própria complexidade da identidade, sua formação progressiva e não linear" e "suas contradições se tornaram os protagonistas dos problemas biográficos com que se deparam os historiadores" (Levi, 1996, p. 173). Ao reconhecermos as limitações das evidências do passado, o caráter condicionado da pesquisa e as dimensões discursivas do nosso ofício, a biografia emerge como uma narrativa fragmentada, mas não menos essencial.

As figurações da escrita biográfica alimentaram-se da aproximação com o texto literário, pois "livre dos entraves documentais, a literatura comporta uma infinidade de modelos e esquemas biográficos que influenciaram amplamente os historiadores" (Levi, 1996, p. 168). Estes, por sua vez, já parecem não demonstrar grande incômodo com o uso da imaginação na ausência de indícios ou vestígios mais seguros dos atos do cotidiano e têm se mostrado cada vez mais à vontade para admitir a parcialidade de suas narrativas e o alcance limitado de suas conclusões.

Poderíamos definir as questões que foram aqui partilhadas como o sintoma de um mal-estar causado pelas pesquisas de recorte biográfico. Tais questóes colocaram em xeque a possibilidade de restituirmos em sua integralidade a vida de um indivíduo e a crença de que a trajetória humana possa estar fielmente entrelaçada aos fenômenos sociais, ou que estes possam claramente delimitar e circunscrever a ação individual. Elas ajudaram também a destacar as incertezas e os desvios que predominam em toda relação social, na qual os atores não contam com guias normativos capazes de prever ou limitar, sem ambivalências, os efeitos dos seus atos, já que nenhum sistema é suficientemente estruturado para eliminar todas as possibilidades de escolha, interpretação, manipulação e negociação das regras sociais.

As pesquisas biográficas tornaram possível, com variações de grau e escalas, o redimensionamento de várias problemáticas concernentes à escrita da história (Avelar, 2010) e às relações sociais. Elas evitaram a formulação de paisagens monolíticas do passado, mostrando, ao contrário, que se as condições de desigualdade entre os indivíduos limitaram o campo de possibilidades e de 
escolhas, sempre deixaram margens de manobra, através das quais os homens puderam se movimentar socialmente e promover mudanças, mesmo que pequenas, em seu meio. A escrita biográfica revelar-se-ia, portanto, um locus privilegiado, não mais para o acesso ao universal, como imaginava Dilthey, mas para a revalorização dos atores sociais, alargando nossa compreensão do passado sem tomá-lo como uma unidade dada e coerente, mas como um campo de conflitos e de construção de projetos de vida.

A alusão a Foucault não sugere que seu trabalho sobre Pierre Rivière seja próximo de qualquer modelo a ser seguido para uma escrita biográfica contemporânea. Ela apenas remonta a uma possível resposta para a perene força humana de buscar narrar e compreender o outro e sinaliza com a consideração das pluralidades discursivas que envolvem a moldura de uma existência, incluindo as próprias escritas de si. Sobre estas, em particular, convém ressaltar o papel que ocupam na apresentação da vida de Rivière e Barbin. Elas demonstram, ao contrário de certas interpretações que demarcam para Foucault um lugar privilegiado no panteão dos autores estruturalistas, que o indivíduo não está inteiramente desprovido de espaços de ação e intervenção nos sistemas normativos. Esses relatos, não obstante o seu uso como peça integrante de uma disciplinarização jurídica, afirmam a palavra, fazem emergir a voz silenciada, revelam uma dada interioridade. Enfim, exalam vida.

Contar vidas, narrar experiências e representar trajetórias seguem como anseios demasiadamente humanos. A proliferação de textos biográficos reitera a aposta efetivada por sucessivas gerações. Por outro lado, tem se tornado cada vez mais evidente a inadequação da biografia em campos intelectuais rígidos. A flexibilidade e o hibridismo do gênero biográfico têm convertido o biógrafo num hábil manipulador de erudição documental e de vocação romanesca. Suplantando os modelos heroico e modal, viveríamos hoje uma "idade hermenêutica" da biografia, na qual a exemplaridade e o personagemsíntese já não mais possibilitam captar todas as fraturas da existência individual (Dosse, 2009, p. 15). A aposta reside aqui na atribuição de significados ao ato biográfico que pode conduzir a uma multiplicidade de outros sentidos. Atento aos riscos dessa modalidade de uso da biografia, Giovanni Levi (1996, p. 178) nos alerta para o fato de que

[...] essa abordagem hermenêutica parece redundar na impossibilidade de escrever uma biografia. Mesmo assim, ao sugerir que é preciso abordar o material biográfico de maneira mais problemática, rejeitando a interpretação 
unívoca das trajetórias individuais, ela estimulou a reflexão entre os historiadores, levando-os a utilizar as formas narrativas de modo mais disciplinado e a buscar técnicas de comunicação mais sensíveis ao caráter aberto e dinâmico das escolhas e das ações.

Não nos parece exagerado admitir que nos trabalhos biográficos mais recentes a ênfase se direcionou para a apreensão das pluralidades identitárias e das sucessivas, contraditórias e descontínuas formas de configuração da subjetividade. O historiador-biógrafo não mais se contenta com a apreensão da verdade factual do seu personagem a partir do trabalho documental. Há outro domínio, "que consiste em indagar a respeito do desenvolvimento de sentidos plurais que a personagem biografada carrega na história até nossos dias" (Dosse, 2009, p. 346). A matéria vida continua sendo fina e envereda por tramas, teias discursivas que constituem parte integrante da sua historicidade e possuem efeitos de verdade tanto quanto efeitos de sentido.

\section{Referências}

ALBUQUERQUE JÚNIOR, D. História: a arte de inventar o passado: ensaios de teoria da História. São Paulo: Edusc, 2007.

ANKERSMIT, F. R. Historiografia e pós-modernismo. Topoi, Rio de Janeiro, v. 2, jan./jun. 2001.

AMARAL, A. Sobre a memória em Jacques Derrida. In: NASCIMENTO, E.; GLENADEL, P. Em torno de Jacques Derrida. Rio de Janeiro: Sette Letras, 2000. p. 23-38.

ARFUCH, L. El espacio biográfico: dilemas de la subjetividad contemporánea. Buenos Aires: Fondo de Cultura, 2010.

AVELAR, A. de S. A biografia como escrita da História: possibilidades, limites e tensões. Dimensôes, v. 24, 2010.

BAUDRILLARD, J. A ilusão vital. Rio de Janeiro: Civilização Brasileira, 2001.

BAUMAN, Z. Vida líquida. Rio de Janeiro: Jorge Zahar, 2007. . A sociedade individualizada: vidas contadas e histórias vividas. Rio de Janeiro: Jorge Zahar, 2008. 
BENJAMIN, W. O narrador. In: BENJAMIN, W. Obras escolhidas: vol. 1: magia e técnica, arte e política. São Paulo: Brasiliense, 1994.

BOURDIEU, P. A ilusão biográfica. In: AMADO, J.; FERREIRA, M. de M. Usos e abusos da história oral. Rio de Janeiro: Editora da FGV, 1996.

DAMASCENO, D. Entre múltiplos eus: os espaços da complexidade. Tese (Doutorado em Letras)-Pontifícia Universidade Católica, Rio de Janeiro, 1999.

DELEUZE, G. Pourparlers. Paris: Minuit, 1990.

. Post-scriptum: sobre as sociedades de controle. In: DELEUZE, G. Conversações. São Paulo: Editora 34, 1992.

DOSSE, F. O desafio biográfico: escrever uma vida. São Paulo: Edusp, 2009.

FOUCAULT, M. Vigiar e punir: o nascimento das prisões. 15. ed. Petrópolis: Vozes, 1987. . Dits et écrits. Paris: Gallimard, 1994.

. Eu, Pierre Rivière, que degolei minha mãe, minha irmã e meu irmão. 8. ed. São Paulo: Graal, 2003.

. Microfísica do poder. Rio de Janeiro: Graal, 1999.

. O sujeito e o poder. In: DREYFUS, H.; RABINOW, P. Foucault: uma trajetória filosófica: para além do estruturalismo e da hermenêutica. Rio de Janeiro: Forense Universitária, 1995.

HARTOG, F. O tempo desorientado. Tempo e história. Como escrever a história da França. Anos 90, Porto Alegre, n. 7, jul./1997.

HUYSSEN, A. Seduzidos pela memória. Rio de Janeiro: Aeroplano, 2000.

JAMESON, F. Pós-modernismo: a lógica cultural do capitalismo tardio. São Paulo: Ática, 1996.

LEVI, G. Os usos da biografia. In: AMADO, J.; FERREIRA, M. de M. Usos e abusos da história oral. Rio de Janeiro: Editora da FGV, 1996.

MAUSS, M. Une catégorie de l'espirit humaine, la notion de personne, celle de moi. In: MAUSS, M. Sociologie et anthropologie. Paris: PUF, 1950.

NEVES, L. M. B. P. das. A biografia de D. João VI: implicações teóricas e metodológicas. In: NEVES, L. M. B. P. das et al. (Org.). Estudos de historiografía brasileira. Rio de Janeiro: Editora da Fundação Getúlio Vargas, 2011. 
REVEL, J. A biografia como problema historiográfico. In: REVEL, J. História e historiografia: exercícios críticos. Curitiba: Editora da UFPR, 2010.

SCHMIDT, B. B. Biografia: um gênero de fronteiras entre a história e a literatura. In: RAGO, M.; GIMENES, R. A. de O. (Org.). Narrar opassado, repensar a história. Campinas: Unicamp, 2000.

SIBILIA, P. La intimidad como espetáculo. Buenos Aires: Fondo de Cultura Económica, 2009.

Resumo: Disseminou-se a ideia de que a pós-modernidade fragmentou o sujeito e fez emergir suas múltiplas identidades, traços e marcas. Essa explosão de subjetividades tem sido acompanhada de dúvidas e incertezas quanto à escrita biográfica. Ela é capaz de restituir, numa moldura textual, as complexidades de uma existência? A vida seria redutível a um conjunto de tropos organizados em uma narrativa? Este artigo tem como objetivo principal realizar algumas considerações sobre os dilemas e as possibilidades da biografia em nosso tempo de aceleração tecnológica e informacional, retomando, ainda, algumas questões formuladas por Michel Foucault sobre as relações entre vida e discurso.

Palavras-chave: escrita, biografia, subjetividades.

\title{
Contemporary subjectivities and biographical writing: limits, challenges and possibilities
}

\begin{abstract}
It was disseminaded that the postmodernity fragmented the subject and made to emerge its multiple identities, traces and features. This explosion of subjectivities has been accompanied of doubts and uncertainties about the biographical writing. Is she able to restitute, in a textual frame, the complexities of an existence? Will be the life reducible to a set of tropos arranged in a narrative? This article has as principal objective to achieve some considerations about the dilemmas and possibilities of the biography in our time of technological and informational accelerating and, further, to recapture some questions formulated by Michael Foucault about the relationships between life and discourse.
\end{abstract}

Keywords: writing, biography, subjectivities.

Recebido em 02/10/2011

Aprovado em 12/11/2011 